\title{
Profile of immune cell populations in an early-onset Parkinson's disease patient (EOPD)
}

\author{
Martin Eduardo Torres-Velasco ${ }^{1,2}$, Jaquelin Leyva-Hernández ${ }^{1,2}$, Asiel Arce-Sillas ${ }^{1,2}$, Mayela Rodriguez-Violante ${ }^{2}$ and Laura Virginia \\ Adalid-Peralta ${ }^{1,2 *}$ \\ ${ }^{1}$ Unidad Periférica para el estudio de la Neuroinflamación en Patologías Neurológicas del Instituto de Investigaciones Biomédicas en el Instituto Nacional de \\ Neurología y Neurocirugía Manuel Velasco Suárez. Insurgentes Sur 3877, La Fama, 14269, Ciudad de México \\ ${ }^{2}$ Instituto Nacional de Neurología y Neurocirugía, Manuel Velasco Suárez. Insurgentes Sur 3877, La Fama, 14269, Ciudad de México
}

\begin{abstract}
Young Parkinson's disease (YPD) and early-onset Parkinson's disease (EOPD) are rare entities that can be found in the clinical practice. Few studies have reported the characteristics of immune cell lines in these patients, whose clinical picture is usually more severe than that of Parkinson's disease (PD) patients. Herein, we report the case of a female subject who showed rigidity and bradykinesia at the age of 23 , with no familial history of PD. A control subject, matched by age and sex, was studied in parallel. Pro- and anti-inflammatory cell populations in peripheral blood were analyzed by flow cytometry. Our results showed a decrease in the levels of regulatory cells, including active regulatory T cells (Tregs), resting Tregs, Tr1, Th3, IL-10-producing plasma cells, and CD205-expressing dendritic cells (DCs), along with increased levels of B7.H1-expressing DCs and IL-10-producing B regulatory cells (Bregs) in the patient with respect to the control. With regard to proinflammatory cells, we found lower levels of Th17 cells, CD40- and CD86-expressing DCs, and increased levels of Th1 and Th2 cells in the patient with respect to the control. The early onset of PD could explain the increase of proinflammatory cell lines, noting that the regulatory immune response is reduced, as reported in cases of idiopathic $\mathrm{PD}$. These findings could be related to the rapid and progressive clinical deterioration observed in EOPD patients.
\end{abstract}

\section{Introduction}

Parkinson's disease (PD) is characterized by rigidity, rest tremor, bradykinesia, and postural instability. It is caused by the loss of dopaminergic neurons in the mid-brain substantia nigra pars compacta $[1,2]$. This neurodegeneration is known to be due to the accumulation of $\alpha$-synuclein and the formation of Lewy's bodies in dopaminergic neurons. Cytotoxicity leads to neuron death, resulting in an aberrant control of movements $[1,3]$. It is the second most common neurodegenerative condition, after Alzheimer's disease, with a prevalence of $0.5-1 \%$ in subjects older than 65 years [4]. PD is diagnosed according to criteria issued by the United Kingdom Brain Bank [5], which cover various aspects of the disease, supported by image and pharmacological studies (levodopa test) [6-8]. Young Parkinson's disease (YPD) and early-onset Parkinson's disease (EOPD) are arbitrarily defined as the finding of Parkinsonian signs and symptoms before the age of 21 and before the age of 50, respectively $[9,10]$. While the incidence of PD in senior adults is high, the juvenile or early-onset spectrum has an incidence lower than 5\%. YPD and EOPD often show atypical traits, being rigidity and bradykinesia the most common signs in both disorders. Additionally, the severity and progression of movement disorders are usually disproportionate (including dystonia, ataxia, and spasticity) and are accompanied by early cognitive deterioration and behavior alterations [9,11-14]. These syndromes are rare, heterogeneous, and usually have a familial factor [15]. Most cases have been reported as caused by mutations in the genes PARK-Parkina, PARK-PINK1, or PARK-DJ1. However, parkinsonian disorders were acquired in childhood or early adulthood in some cases [9]. While idiopathic PD is rarely observed in the younger population, postmortem examination has shown the presence of Lewy's bodies in some YPD and EOPD cases [16].
The immune response in YPD and EOPD is known to be aberrant; the inflammatory response is mediated by effector subpopulations of activated B and T helper cells. Higher levels of INF- $\gamma$ with respect to controls have been observed [16,17]. Additionally, there is evidence of cytotoxicity on dopaminergic neurons by infiltration of peripheryrecruited Th17 cells into the central nervous system (CNS). Mogui et al. [17] reported a 2-5-fold increase in the levels of inflammatory populations like activated B cells and Th17 cells in YPD patients with respect to PD patients, being especially relevant the higher levels of Th17 cells in the ventricles. Increased levels of IL-1, IL-2, IL-4, and TGF- $\alpha$ were detected in the ventricular cerebrospinal fluid (VCSF), but were undetectable by lumbar puncture. This suggests that those lymphocytes aberrantly activated in the ventricles are mediating inflammation, contributing to neurodegeneration in YPD and EOPD [16-18]. Another postmortem study observed Lewy's bodies in dopaminergic neurons from an EOPD patient, suggesting a similar pathophysiology to that observed in senior subjects [19].

Thus, this case report is aimed to analyze the regulatory and proinflammatory immune cell populations in blood from a EOPD patient.

${ }^{\star}$ Correspondence to: Laura Adalid-Peralta, PhD, Unidad Periférica para el estudio de la Neuroinflamación en Patologías Neurológicas del Instituto de Investigaciones Biomédicas en el Instituto Nacional de Neurología y Neurocirugía Manuel Velasco Suárez. Insurgentes Sur 3877, La Fama, 14269, Ciudad de México, E-mail: adalid.laura@yahoo.com

Key words: early-onset, idiopatic, immune response, parkinson, proinflammatory, regulated

Received: May 29, 2020; Accepted: June 16, 2020; Published: June 23, 2020 


\section{Case}

A 33 years-old female patient, working as a retailer, with no familial history of neurodegenerative disorders, but with a history of toxic exposure (possibly to rotenone) after working as an agricultural laborer, spraying pesticide on crop fields in her teens, and of indoor exposure to wood smoke until the age of 10 . At the age of 23 , the patient showed symptoms suggestive of $\mathrm{PD}$, like morning rigidity and involuntary tremor in the upper left limb. In time, other symptoms like mild anosmia, short-term memory deficit were added, and the patient fell from her height several times due to brief periods of postural instability. Motor symptoms started with tremor in the upper right limb, fine tremor in the distal region, and muscular rigidity exacerbated by stressful or unnerving situations (bad news, as mentioned the patient). She has suffered from constipation, and over a few months tremor started in the lower right limb, more noticeably in the distal portion and accompanied by muscular rigidity; currently, abnormal movements in her right arm show a greater amplitude. About 10 months ago, the patient showed tremor in the left upper and lower limbs, being less severe in this side. These signs are accompanied by emotional instability and paranoid episodes with persecutory suspicion and fear. PD was diagnosed 6 months ago by clinical examination, according to the criteria issued by the United Kingdom Brain Bank; the patient showed an improvement of $85 \%$ in the levodopa test. The UPDRS score was 63 , Hoen and Yahr stage was 2; Schwab \& England scale score was 100\%; and MOCA score was 19, suggesting a significant cognitive deterioration. Magnetic resonance imaging showed hyperdense areas, suggestive of agglomerated hemosiderin in the inner globus pallidus. Currently, the patient is being administered with levodopa and biperiden, with a good control, but a possible psychiatric pathology is under study.

Control: The control patient is a 31 years-old female subject, matched by body weight and ethnicity with the EOPD patient, with no significant medical history nor diagnosed with a neurodegenerative disorder.

\section{Materials and methods}

Peripheral blood mononuclear cells (PBMCs) were isolated by density gradient from blood samples from a EOPD and a control subject. Then, pro- and anti-inflammatory immune cell populations were analyzed by flow cytometry as described by Álvarez-Luquin, 2019 [20].

\section{Results}

The levels of active and resting Tregs were up to 3 times lower in the EOPD patient with respect to the healthy control (Table 1). Similarly, the levels of $\operatorname{Tr} 1$ and Th3 cells were up to 4 times lower in the EOPD patient. On the other hand, while the levels of plasma cells and IL10 -producing cells were 2 times lowers in the EOPD patient than in the healthy subject, the levels of B7.H1+ dendritic cells (DCs) and IL10 -producing Bregs were 2 times higher in the former; the levels of CD205-expressing DCs were 3 times lower in the EOPD patient than in the control subject. Regarding proinflammatory cell populations, the levels of CD40+- and CD86+- expressing DCs were 3 times lower in the EOPD patient than in the healthy control. The levels of IFN $\gamma$ - and TNFa-producing Th1 cells and IL-4-producing Th2 cells were 2 times high in the EOPD patient with respect to the control. Finally, levels 2 times lower of IL-17- and IL-6-producing cells were found in the EOPD patient (Table 1).
Table 1. Percentages of immune cells subpopulation in PD patient compared to a healthy subject

\begin{tabular}{|c|c|c|}
\hline & $\begin{array}{c}\text { Control } \\
\text { (\% of gated cells) }\end{array}$ & $\begin{array}{c}\text { PD patient } \\
\text { (\% of gated cells) }\end{array}$ \\
\hline \multicolumn{3}{|l|}{ Population markers } \\
\hline T CD4+ lymphocytes & 40.98 & 41.74 \\
\hline T CD8+ lymphocytes & 18.02 & 22.60 \\
\hline B CD19+ lymphocytes & 18.87 & 19.63 \\
\hline CD11c+ dendritic cells (DCs) & 19.922 & 37.400 \\
\hline \multicolumn{3}{|l|}{ Regulatory cells } \\
\hline \multicolumn{3}{|l|}{ Regulatory T cells } \\
\hline Suppressive regulatory $\mathrm{T}$ cells & 0.883 & 0.658 \\
\hline Active $\mathrm{T}$ regs & 0.962 & 0.394 \\
\hline No T regs & 4.446 & 2.937 \\
\hline Resting $\mathrm{T}$ regs & 5.114 & 2.018 \\
\hline $\operatorname{Tr} 1$ & 0.728 & 0.261 \\
\hline Th3 & 1.240 & 0.375 \\
\hline \multicolumn{3}{|l|}{ Regulatory CD8+ cells } \\
\hline Cytolytic CD8+ & 3.019 & 2.670 \\
\hline CD8+ regs & 13.138 & 10.317 \\
\hline Functional CD8+ & 0.032 & 0.036 \\
\hline \multicolumn{3}{|l|}{ Regulatory B cells } \\
\hline Plasma cells & 62.197 & 35.375 \\
\hline IL-10-producing plasma cells & 48.129 & 29.955 \\
\hline Functional B regs & 0.358 & 0.487 \\
\hline IL-10-producing functional B regs & 0.291 & 0.413 \\
\hline $\mathrm{B}$ regs cells & 0.610 & 0.792 \\
\hline \multicolumn{3}{|l|}{ Regulatory dendritic cells } \\
\hline B7.H1+ DCs & 1.804 & 3.092 \\
\hline SLAM 1+ DCs & 0.736 & 0.764 \\
\hline ILT3+ DCs & 12.532 & 10.868 \\
\hline CD205+ DCs & 9.681 & 3.109 \\
\hline \multicolumn{3}{|l|}{ Proinflammatory cells } \\
\hline \multicolumn{3}{|l|}{ Proinflammatory dendritic cells } \\
\hline HLA-DR+ DCs & 18.911 & 15.575 \\
\hline CD40+ DCs & 2.993 & 0.849 \\
\hline CD86+ DCs & 45.750 & 13.568 \\
\hline \multicolumn{3}{|l|}{ Proinflammatory TCD4+ cells } \\
\hline IFN $\gamma$-producing Th1 cells & 0.244 & 0.508 \\
\hline TNF $\alpha$-producing Th1 cells & 0.560 & 1.060 \\
\hline IL-13-producing Th2 cells & 3.149 & 4.044 \\
\hline IL-4-producing Th2 cells & 1.191 & 2.335 \\
\hline IL-17-producing Th17 cells & 2.242 & 1.158 \\
\hline IL-6-producing Th17 cells & 2.060 & 0.872 \\
\hline
\end{tabular}

\section{Discussion}

EOPD is a chronic disorder that impacts severely on patients' quality of life. Various etiologies have been proposed to explain the occurrence of movement disorders at an early age, including a genetic predisposition (either hereditary or acquired) and toxic exposure. These patients show a much higher mortality than idiopathic PD patients [21]. In our case, the EOPD patient showed a disease timeline consistent with previous reports [9,11-14], being morning rigidity and bradykinesia the main signs. The marked decrease in the levels of regulatory cell lines, including CD205-expressing tolerogenic DCs, Tr1 and Th3 cells, active and resting Tregs, and IL-10-producing plasma cells suggests an impaired function of the regulatory immune response in the EOPD patient; this finding is in agreement with the results in idiopathic PD patients reported by Alvarez-Luquin, 2019 
[20]. It is noteworthy that decreased levels of Tr1 and active Treg cells are linked to a rapid cognitive deterioration and a faster progression of neurodegenerative conditions like Alzheimer's disease in murine models [22-24]. However, the levels of IL-10-producing functional B cells were higher in the patient, which suggests that a constant production of IL10 could be having a suppressive effect in the EOPD patient $[25,26]$. On the other hand, we observed a marked contrast between the levels of proinflammatory cells in the patient and the control, with a significant increase in the levels of IFN $\gamma$ - and TNF $\alpha$-producing Th1 and Th2 cells, suggesting that these cell populations could damage dopaminergic neurons, as previously observed $[24,27,28]$. On the other hand, while Th17 cells were recently linked to the progression of PD and its possible autoimmune etiology, the decreased levels of Th17 cells could rule out an autoimmune mechanism in EOPD [29]. The patient's history of toxic exposure could be associated to neurotoxicity, which along with the increased levels of proinflammatory Th1 and Th2 could result in an earlier occurrence of PD signs [17,18,30].

\section{Conclusion}

Our findings demonstrate that, like PD, EOPD shows an immune profile associated to a proinflammatory process that was not appropriately suppressed by a decreased immunoregulatory immune response. These effects could favor a faster progression of motor and cognitive signs and symptoms in an EOPD patient, rapidly degrading the quality of life of these patients.

\section{Acknowledgments}

The authors thank the LABNALCIT-UNAM (CONACYT) for their technical support, in particular Carlos Castellanos Barba, Juan Francisco Rodríguez for his help with copy-editing. The CONACYT SALUD program provided financial support to this study [grant No. 2015-1-261455].

\section{Conflicts of interest}

The authors report no conflict of interest.

\section{References}

1. Hayes MT (2019) Parkinson's Disease and Parkinsonism. Am J Med 132: 802-807. [Crossref]

2. Glass CK, Saijo K, Winner B, Marchetto MC, Gage FH, et al. (2010) Mechanisms Underlying Inflammation in Neurodegeneration. Cell Stem Cell 140: 918-934. [Crossref]

3. Dauer W, Przedborski S (2003) Parkinson's disease: Mechanisms and models. Neuron 39: 889-909. [Crossref]

4. Collins LM, Toulouse A, Connor TJ, Nolan YM (2012) Contributions of central and systemic inflammation to the pathophysiology of Parkinson's disease. Neuropharmacology 62: 2154-2168.

5. Hughes AJ, Daniel SE, Kilford L, Lees AJ (1992) Accuracy of clinical diagnosis of idiopathic Parkinson's disease: A clinico-pathological study of 100 cases. J Neurol Neurosurg Psychiatry 55: 181-184.

6. Rodríguez-Violante M, Cervantes-Arriaga A (2014) La escala unificada de la enfermedad de Parkinson modificada por la Sociedad de Trastornos del Movimiento (MDS-UPDRS): Aplicación Clínica e Investigación 19.

7. Goetz CG, Tilley BC, Shaftman SR, Stebbins GT, Fahn S, et al. (2008) Movement disorder society-sponsored revision of the unified parkinson's disease rating scale (MDS-UPDRS): Scale presentation and clinimetric testing results. Mov Disord 23: 2129-2170

8. Hoehn MM, Yahr MD (1967) Parkinsonism: Onset, progression, and mortality. Neurology 17: 427-442. [Crossref]

9. Niemann N, Jankovic J (2019) Juvenile parkinsonism: Differential diagnosis, genetics, and treatment. Park Relat Disord 67: 74-89.
10. Anwar A, Saleem S, Akhtar A, Ashraf S, Ahmed MF, et al. (2019) Juvenile Parkinson Disease. Cureus 11.

11. Muthane UB, Swamy HS, Satishchandra P, Subhash MN, Rao S, et al. (1994) Early onset Parkinson's disease: Are juvenile- and young-onset different? Mov Disord 9: 539544. [Crossref]

12. Bostantjopoulou S, Logothetis J, Katsarou Z, Mentenopoulos G (1991) Clinical observations in early and late onset Parkinson's disease. Funct Neurol 6: 145-149.

13. Giovannini P, Piccolo I, Genitrini S, Soliveri P, Girotti F, et al. (2015) Early-onset Parkinson's disease. Mov Disord 6: 36-42.

14. Quinn N, Critchley P, Marsden CD (1987) Young onset Parkinson's disease. Mov Disord 2: 73-91.

15. Mehanna R, Jankovic J (2019) Young-onset Parkinson's disease: Its unique features and their impact on quality of life. Park Relat Disord 65: 39-48.

16. Gibb WRG, Narabayashi H, Yokochi M, Iizuka R, Lees AJ, et al. (1991) New pathologic observations in juvenile onset parkinsonism with dystonia. Neurology 41: 820-822. [Crossref]

17. Mogi M, Harada M, Narabayashi H, Inagaki H, Minami M, et al. (1996) Interleukin (IL)-1 $\beta$, IL-2, IL-4, IL- 6 and transforming growth factor- $\alpha$ levels are elevated in ventricular cerebrospinal fluid in juvenile parkinsonism and Parkinson's disease. Neurosci Lett 211: 13-16.

18. Bessler H, Djaldetti R, Salman H, Bergman M, Djaldetti M, et al. (1999) IL-1 $\beta$, IL-2, IL-6 and TNF- $\alpha$ production by peripheral blood mononuclear cells from patients with Parkinson's disease. Biomed Pharmacother 53: 141-145.

19. Schrag A, Schott JM (2006) Epidemiological, clinical, and genetic characteristics of early-onset parkinsonism. Lancet Neurol 5: 355-363.

20. Álvarez-Luquín DD, Arce-Sillas A, Leyva-Hernández J, Sevilla-Reyes E, Boll MC, et al. (2019) Regulatory impairment in untreated Parkinson's disease is not restricted to Tregs: other regulatory populations are also involved. J Neuroinflammation 16: 212. [Crossref]

21. Schrag A, Ben-Shlomo Y, Brown R, Marsden CD, Quinn N, et al. (1998) Young-onset Parkinson's disease revisited - Clinical features, natural history, and mortality. Mov Disord 13: 885-894.

22. Dansokho C, Ait Ahmed D, Aid S, Toly-Ndour C, Chaigneau T, et al. (2016) Regulatory $\mathrm{T}$ cells delay disease progression in Alzheimer-like pathology. Brain 139: 1237-1251.

23. Henkel JS, Beers DR, Wen S, Rivera AL, Toennis KM, et al. (2013) Regulatory Tlymphocytes mediate amyotrophic lateral sclerosis progression and survival. EMBO Mol Med 5: 64-79. [Crossref]

24. Beers DR, Henkel JS, Zhao W, Wang J, Huang A, et al. (2011) Endogenous regulatory T lymphocytes ameliorate amyotrophic lateral sclerosis in mice and correlate with disease progression in patients with amyotrophic lateral sclerosis. Brain 134: 1293-1314.

25. David B, Lewis M (2012) Neonatal T Cell Immunity and Its Regulation by Innate Immunity and Dendritic Cells. In: Richard A. Polin M, editor. Hematol Immunol Infect Dis 20: 189-211.

26. Rosser EC, Mauri C (2015) Regulatory B Cells: Origin, Phenotype, and Function. Immunity 42: 607-612.

27. Rathnayake D, Chang T, Udagama P (2013) Selected serum cytokines and nitric oxide as potential multi-marker biosignature panels for Parkinson disease of varying durations: a case-control study. Springer n.d.

28. Kouchaki E, Kakhaki RD, Tamtaji OR, Dadgostar E, Behnam M, et al. (2018) Increased serum levels of TNF- $\alpha$ and decreased serum levels of IL-27 in patients with Parkinson disease and their correlation with disease severity. Clin Neurol Neurosurg 166: 76-79. [Crossref]

29. Sommer A, Maxreiter F, Krach F, Fadler T, Grosch J, et al. (2018) Th17 lymphocytes induce neuronal cell death in a human iPSC-based model of parkinson's disease. Cell Stem Cell 23: 123-131.

30. Johnson ME, Stringer A, Bobrovskaya L (2018) Rotenone induces gastrointestina pathology and microbiota alterations in a rat model of Parkinson's disease. Neurotoxicology 65: 174-185. [Crossref]

Copyright: (C2020 Torres-Velasco ME. This is an open-access article distributed under the terms of the Creative Commons Attribution License, which permits unrestricted use, distribution, and reproduction in any medium, provided the original author and source are credited. 